\title{
INCLUSÃo de CRIANÇAS COM SíNDROME de DOWN E PARALISIA CEREBRAL NO ENSINO FUNDAMENTAL I: COMPARAÇÃo DOS RELATOS DE MÃES E PROFESSORES ${ }^{1}$ INCLUSION OF CHILDREN WITH DOWN SYNDROME AND CEREBRAL PALSY IN ELEMENTARY SCHOOLS: COMPARISON BETWEEN PARENTS' AND TEACHERS' REPORTS
}

\author{
Clara Regina Abdalla FERRAZ² \\ Marcos Vinícius de ARAÚJO3 \\ Luiz Renato Rodrigues CARREIRO ${ }^{4}$
}

RESUMO: o princípio fundamental da escola inclusiva é de que todas as crianças aprendam juntas, independentemente de dificuldades ou diferenças. Hoje, há necessidade de revisão da inclusão de alunos com deficiências e da função da escola como contribuinte do seu desenvolvimento. Diante disso, percebe-se a importância da interação pais e escola para efetivação desse processo. Assim, este trabalho buscou conhecer o processo de inclusão do aluno com Síndrome de Down (SD) e Paralisia Cerebral (PC), a partir da comparação dos relatos de pais e professores e analisar como sua interação afeta o processo de inclusão. Participaram deste estudo 4 mães com filhos com PC, 4 mães com filhos com SD e 8 respectivos professores dessas crianças, do ensino público regular de um município na grande São Paulo. Utilizou-se uma entrevista estruturada construída pelos pesquisadores e adaptada para pais e professores. Para análise foram identificadas as categorias que emergiram dos relatos dos grupos. Como resultados observaram-se: oportunidade da inclusão diminuir o preconceito; a expectativa dos pais em matricular o filho na escola regular como possibilidade de aprender a ler e a escrever ao menos o nome. Por outro lado, os professores declaram não se sentirem preparados para este trabalho; entretanto, mesmo sem orientações, recursos e estrutura física adequada, trabalham para efetivação do aprendizado em sala de aula. A escola deve possibilitar condições para que os pais e professores se comuniquem de forma adequada e assim compartilhem conhecimentos indispensáveis para a inclusão e aprendizado efetivo de crianças com SD e PC.

PALAVRAS-CHAVE: educação especial; Síndrome de Down; paralisia cerebral; inclusão; família.

\begin{abstract}
The fundamental principle of inclusive schools is that all children learn together, no matter their differences or difficulties. Currently, there is a need to review the inclusion of students who have disabilities, and the role of schools as contributors to their development. Thus, the importance of parent-school interaction can be a key to the effectiveness of this process. This paper aimed to understand the inclusion process of students with Down Syndrome (DS) and Cerebral Palsy (CP) by comparing parent and teacher reports and analyzing how their interaction affects the process of inclusion. The participants were four mothers of children with $\mathrm{CP}$, four mothers of children with DS and these children's eight teachers, who work in regular public school in greater São Paulo. A semi-structured interview was developed by the researchers and adapted for parents and teachers. The categories of analysis emerged from the reports. The results indicated: the opportunity of inclusion diminishes prejudice; parents expect that when they enroll their children in mainstream education, they will at least learn to read and write their own names. Teachers reported they did not feel prepared for this job; nevertheless, even without orientation, resources and appropriate physical structure, they seek to achieve
\end{abstract}

${ }^{1}$ Este trabalho foi defendido como Dissertação de Mestrado do Programa de Pós-Graduação em Distúrbios do Desenvolvimento da aluna Clara Regina Abdalla Ferraz sob orientação do professor Dr. Luiz Renato Rodrigues Carreiro. Apoio Financeiro: Mackenzie

${ }^{2}$ Mestre em Distúrbios do Desenvolvimento da Universidade Presbiteriana Mackenzie. claraabdalla@ig.com.br

${ }^{3}$ Psicólogo pelo Mackenzie, Mestre e Doutorando em Distúrbios do Desenvolvimento da Universidade Presbiteriana Mackenzie. Professor do Curso de Psicologia da Universidade Presbiteriana Mackenzie. marcosaraujo@mackenzie.br

${ }^{4}$ Psicólogo pela UFF, Mestre e Doutor em Fisiologia Humana pelo ICB-USP, Professor Adjunto I do Programa de PósGraduação em Distúrbios do Desenvolvimento do Centro de Ciências Biológicas e da Saúde da Universidade Presbiteriana Mackenzie. luizrenato.carreiro@mackenzie.br 
an effective learning environment in the classroom. Schools should provide conditions for proper parentteacher communication, to enable them to share essential information for the inclusion and effective learning of children with DS and CP.

KEYWORDS: Special Education; Down Syndrome; Cerebral Palsy; Inclusion, Family.

\section{INTRODUÇÃO}

O princípio fundamental da escola inclusiva é o de que todas as crianças deveriam aprender juntas, independentemente de dificuldades ou diferenças que possam apresentar. As escolas inclusivas devem reconhecer e responder às diversas necessidades de seus alunos, acomodando estilos e ritmos diferentes de aprendizagem. Devem assegurar a todos uma educação de qualidade, por meio de currículo apropriado, modificações organizacionais, estratégias de ensino, uso de recursos e parcerias com a comunidade. Nas escolas inclusivas, as crianças com necessidades educacionais especiais devem receber qualquer apoio extra de que possam precisar, para que lhes seja assegurada uma educação efetiva (UNESCO, 1994).

Há, na educação inclusiva, a introdução de uma nova maneira de ver os outros e de ver a educação. Assim, inclusão significa modificação da sociedade como pré-requisito para a busca do desenvolvimento e exercício da cidadania. Desse modo, há que se preparar a escola para incluir nela o aluno com deficiência, a fim de que os benefícios sejam múltiplos para todos os envolvidos com a educação: os alunos, os professores e a sociedade (FREITAS, 2006). É nesse contexto que as políticas públicas de educação estão inseridas.

As diretrizes apontadas pelo Conselho Nacional de Educação desde 1994, a partir de decretos, resoluções e leis, instituem as ações básicas para implementação das propostas de educação inclusiva. Para definição de uma política nacional para a educação, essas ações governamentais buscam estratégias efetivas para a garantia de ações em nível federal, estadual e municipal (BRASIL, 2007).

De acordo com Marins e Matsukura (2009), as discussões e garantias teóricas acerca das políticas internacionais e nacionais, bem como as diretrizes governamentais para a educação inclusiva, são bem consistentes. Não obstante, considera-se que, neste momento, cabe também investigar sua forma de implementação. Nessa perspectiva, fomentam-se iniciativas que buscam verificar como o aparato legal e as políticas públicas vêm garantindo a efetivação das propostas inclusivas.

Hoje, há necessidade de se rever a inclusão de alunos com algumas deficiências e que requerem mais cuidados, atenção, assim como a verdadeira função da escola como contribuinte em seu desenvolvimento. Souza (2007) pesquisou a inclusão escolar em seis escolas públicas, três em Portugal e três no Brasil, e concluiu que as dificuldades encontradas nos dois países são semelhantes. Por exemplo, ele cita a falta de preparo dos profissionais e descreve que não é a sociedade que se adapta para recepcionar a criança com deficiência, e sim a criança que vai se adaptando para interagir com a sociedade. Outros autores corroboram 
que a necessidade de formação dos professores é crucial para a eficácia da inclusão (MELO; ROCHAI, 2008; LEONARDO, 2008; VITALIANO, 2007; MARTINS; MELLO, 2007; ARTIOLI, 2006).

Arsenio (2007) fez um estudo a partir de dissertações e teses produzidas nas principais universidades paulistas e defendidas no ano de 2002 e 2005, investigando quais eram os obstáculos encontrados para a inclusão escolar da pessoa com deficiência. Dentre eles observou ausência de intervenção escolar que efetive o acesso à leitura e à escrita, sala de aulas numerosas, necessidade de maior investimento na escola para melhorar as condições do trabalho docente, e formação distanciada da realidade, com conteúdos que não possibilitam aos professores perceber o aluno como um indivíduo que constrói o seu conhecimento.

Relacionado a essa questão de aprendizagem, Leonardo (2008) demonstra que as escolas brasileiras, especialmente as públicas, têm enfrentado muitas dificuldades, pois não conseguem proporcionar aprendizagem acadêmica nem mesmo às crianças que não possuem deficiência. Tal autor conclui, em seu trabalho, que a inclusão escolar vem se efetivando sem a infraestrutura adequada, carecendo tanto de recursos materiais quanto de recursos humanos, podendo, desse modo, trazer prejuízos ao processo de inclusão que vem acontecendo em escolas públicas. Tal fato evidencia necessidade de maior investimento no processo educacional com vista a efetivação da inclusão escolar.

Para avaliar o processo de inclusão no ensino fundamental, este artigo tomará por base o relato de mães e professores de crianças com Síndrome de Down e Paralisia Cerebral, em função das particularidades dessas deficiências (como déficits intelectuais e motores) com relação ao processo de aprendizagem e sua recorrência no sistema público de ensino.

\section{SíNDROME De Down}

A denominação Síndrome de Down (SD) é resultado da descrição de Langdon Down, médico inglês que pela primeira vez identificou, em 1866, as características de uma criança com essa síndrome (SCHWARTZMAN, 2003). Em 1959, o médico francês Jérôme Lejeune identificou a presença de um cromossomo a mais em indivíduos com SD (caracterizando, assim, uma trissomia do cromossomo 21), e essa identificação, até hoje, é considerada a principal causa genética de deficiência mental (PUESCHEL, 2007), apresentando prevalência de 1:700 a 1:750 nascimentos (SHERMAN et al., 2007). Entretanto, é de grande importância compreender, seja para o aprendizado acadêmico, seja para as relações familiares, que, tanto as habilidades intelectuais, quanto as sociais de crianças com SD, são maximizadas, quando elas são criadas em um ambiente de apoio, com estimulação adequada (STRAY-GUNDERSEN, 2007).

A educação da criança com SD é uma atividade complexa. Entre outras razões, isso se dá pela necessidade de se introduzir adaptações de ordem curricular 
que requerem cuidadoso acompanhamento de educadores, dos pais, da sociedade. As dificuldades de aprendizagem, os distúrbios de conduta e a problemática de sua integração completam, mas não esgotam o quadro da educação do aluno com SD (MILLS, 2003).

Segundo Cunningham (2008), a escola indicada para a criança é aquela que oferece uma boa estrutura. Estudar em uma escola regular ruim trará menos benefícios do que estudar em uma escola especial razoável, ou o contrário disso. Existem evidências de que ter uma criança com deficiências em uma turma regular motiva outras crianças a se tornarem mais tolerantes e compreensivas. Isso depende das características da criança com deficiência. Se ela tiver problemas de comportamento, ou se não conseguir se envolver com outras, o efeito pode ser contrário. Em se tratando de crianças com SD, conforme Mills (2003), a escola deve fornecer participação adequada que lhes permita a aquisição de novos conhecimentos, a fim de que possam acompanhar o progresso dos colegas.

As atividades em sala de aula devem proporcionar a interação entre os colegas e não se tornarem motivos de separação. Com base nessa linha de pensamento, Teixeira e Kubo (2008) realizaram uma pesquisa com 103 colegas de turma de alunos com SD, estudantes de uma escola regular de uma cidade do sul do Brasil. Constataram que, quanto maior o desenvolvimento acadêmico e o grau de participação nas atividades escolares, maior era a possibilidade de o aluno com SD ser considerado amigo por seus colegas.

É necessário destacar a aparência física dos alunos com SD como outra variável determinante da forma como são percebidos por seus professores e colegas de turma. Uma pessoa com SD é facilmente identificada como "deficiente" ou "diferente", pelo conjunto de características físicas decorrentes da síndrome. A aparência evidente da anomalia genética faz com que pessoas com a SD sejam percebidas por meio de estereótipos e preconceitos, podendo ser facilmente subestimadas em suas competências em diversas áreas (OMOTE, 1990).

Voivodic (2008), ao analisar o projeto “Educar Mais 1", que é um programa de inclusão de crianças com Síndrome de Down em classes comuns no ensino regular, relacionou vários aspectos importantes para que a inclusão da criança com SD ocorra. Para cada 5 crianças existe um mediador que tem como função estabelecer a ponte entre as famílias e profissionais da educação no desenvolvimento de projetos específicos para cada contexto escolar. É fundamental a participação e o comprometimento dos pais, da escola, dos professores e dos colegas das crianças participantes. Dentre esses aspectos pode-se citar a concepção de inclusão como processo gradativo e que muitas escolas ainda não estão preparadas para ele; apoio ao professor para lidar com a classe como um todo, capacitação de todos os funcionários da escola, adequação curricular e apoio a família.

Martins (1999) realizou uma pesquisa em escolas regulares da cidade de Natal/RN e descreveu que a inclusão de alunos com SD foi percebida como construtiva para o desenvolvimento de professores e para os outros alunos. A 
convivência com colegas com SD proporcionou maior grau de interação na turma, a construção de vínculos afetivos e a diminuição de preconceitos e estereótipos em relação aos colegas com a síndrome. Luiz e colaboradores (2008) analisaram artigos sobre a inclusão de crianças com SD na rede regular de ensino da Nova Zelândia, Holanda, Reino Unido e Estados Unidos e apontaram a boa interação dos pais com a escola como primordial fator positivo, pois eles têm experiências e habilidades para ensinar o próprio filho. Assim, observa-se que a inclusão do aluno com SD poderá acontecer de forma satisfatória, tanto para a escola, como para a família (TEIXEIRA; KUBO, 2008; MARTINS, 1999; LUIZ et al., 2008, VOIVODIC, 2008). Fica claro, também, que o sucesso desse processo dependerá do trabalho conjunto de professores, diretores e demais funcionários envolvidos, devendo-se buscar alternativas para eliminar barreiras que impeçam o desenvolvimento do aluno.

\section{Paralisia cerebral}

Paralisia Cerebral (PC) é uma expressão abrangente para diversos distúrbios causados por uma lesão cerebral que ocorre antes, durante ou nos primeiros dias depois do nascimento (BOBATH, 1979; GERALIS, 2007). Dependendo de sua localização e gravidade, a lesão pode causar distúrbios de movimento e também deficiência mental, convulsões, distúrbios de linguagem, transtornos de aprendizagem e problemas de visão e audição (GERALIS, 2007; FONSECA; LIMA, 2008).

De acordo com Fonseca e Lima (2008), a incidência de crianças com PC está entre 1 e 2 por 1.000 nascidos vivos, nos países desenvolvidos, enquanto nos países em desenvolvimento está estimada em 7 por 1.000 nascidos vivos. A paralisia cerebral pode ser ocasionada por doença (como rubéola), efeitos de radiação ou acidentes sofridos pela mãe durante a gestação. Acidentes na hora do parto, que ocasionem a falta de oxigenação no cérebro da criança, ou, ainda, algum traumatismo craniano ou doença sofrida pela criança durante o período de amadurecimento do cérebro também podem ser compreendidas como causas de paralisia cerebral (SATOW, 2000).

De acordo com o material publicado pelo Ministério da Educação e Cultura "Saberes e Práticas da Inclusão" (BRASIL, 2006), a inclusão de crianças com múltiplas deficiências na educação regular não depende do grau de severidade da deficiência ou do nível de seu desempenho intelectual; mas da possibilidade de interação, acolhida, socialização, adaptação do indivíduo ao grupo e, principalmente, da modificação da escola para atendê-lo. Como proposta inicial de tal documento, considera-se que, para que a inclusão escolar seja satisfatória, o acesso aos serviços educacionais que estão disponíveis na sociedade deve ser assegurado, o mais cedo possível, também para aquelas crianças com problemas mais severos no desenvolvimento. Enfatiza-se, também, que incluir não significa apenas inserir crianças na sala de aula, e sim adaptar objetivos, atividades ou, se preciso dar mais tempo para que a criança consiga aprender. 
Souza (2005) aponta que devido ao fato da PC envolver deficiências associadas, como motoras, sensoriais e/ou cognitivas, a inclusão escolar desses alunos representa enorme desafio. Para professores, de um modo geral, essa é uma dificuldade, pois predomina ainda o desconhecimento sobre possível integridade das capacidades cognitivas. Com isso, mantém-se o preconceito de que grande parte do universo de alunos com sequelas de PC é incapaz de aprender a ler, a escrever e participar ativamente das atividades escolares. Souza (2005) destaca que, em se tratando de condições de aprendizagem do aluno com PC com déficit intelectual severo, se houvesse pessoas disponíveis em sala de aula, atuando como cuidadoras das necessidades de vida diária desses alunos, a professora teria mais tempo para elaborar atividades adaptadas. Esses alunos precisam de cuidados especiais, como, higienização, auxílio para refeição, entre outros, mas precisam, também, ser estimulados à participação e incluídos nas atividades pedagógicas comuns da sala de aula.

Gomes (2006) observou que muitos professores apresentavam atitudes negativas quanto à política educacional inclusiva. Talvez o mais grave, no entanto, foi perceber que uma parcela significativa dos participantes não considerava ser de sua responsabilidade e competência educar alunos com PC. Tal trabalho evidencia a necessidade de revisão de crenças, convicções, valores e preconceitos dos docentes, para que, dessa forma, eles adquiram atitudes positivas para atuar como agentes de inclusão escolar.

Assim, é possível verificar que existem muitas diferenças e especificidades no processo inclusivo de alunos com PC eSD. Além da preparação da escola, como descrito anteriormente, a família tem muito a contribuir para esse processo; no entanto, a maioria das escolas públicas não tem a participação efetiva da família. Tal questão será discutida na próxima seção.

\section{RELAÇÃO ENTRE PAIS E PROFESSORES NO PROCESSO DE INCLUSÃO}

Ribeiro e Andrade (2006) buscaram compreender como vem sendo vivenciada a relação entre a família e a escola pública, envolvendo em seu estudo agentes escolares, professores de $3^{\mathrm{a}}$ e $4^{\mathrm{a}}$ série e responsáveis pelos alunos em suas residências. Concluíram que a escola parece se relacionar com as famílias prioritariamente no sentido de uma exigência de complementaridade, com relação a suas expectativas e por meio da atribuição de responsabilidade aos alunos, por suas próprias dificuldades. Não parece haver um movimento sistemático no sentido de compreender a realidade vivida pelos alunos e suas famílias.

Silva e Mendes (2008) realizaram um estudo com o objetivo de identificar e descrever os componentes dos profissionais da escola e dos familiares de crianças com deficiência que, na perspectiva dos dois lados, são propiciadores e mantenedores de uma parceria colaborativa, efetiva e bem sucedida. Foram identificados alguns comportamentos que devem ser emitidos pelos familiares na 
parceria colaborativa: comunicar-se com os profissionais, ser responsável pela educação do filho, manter expectativas adequadas, aceitar a deficiência do filho, respeitar os profissionais e reconhecer o trabalho deles, confiar no trabalho desenvolvido, questionar os profissionais de modo adequado, garantir a frequência do aluno, visitar a escola e participar das atividades.

No que diz respeito aos comportamentos esperados pelos profissionais em relação às famílias, Silva e Mendes (2008) descrevem a importância da comunicação como um processo que ajuda a manter expectativas adequadas, respeito aos alunos e os familiares de forma amistosa, separando problemas pessoais da atividade profissional e incorporando no trabalho sugestões fornecidas pelos familiares, incentivando sua participação. Assim, pode-se concluir que a sincronia entre esses parceiros é fundamental à medida que reconhecem seus papeis e promovem o respeito mútuo, comunicação, confiança, participação, amabilidade, sinceridade e seriedade na construção da inclusão.

Diante do exposto, percebe-se a importância da interação pais e escola para efetivação do processo de inclusão. Para compreender melhor esta relação, este trabalho tem como objetivo conhecer o processo de inclusão do aluno com SD e PC, a partir da comparação dos discursos de pais e professores e, com isso, avaliar como a comunicação entre eles pode afetar o processo de inclusão. Desse modo, a comparação dos resultados com base nesses diagnósticos permitirá compreender quais problemas ou experiências satisfatórias, vividas por mães e professores, são mais presentes em cada uma dessas deficiências e se eles (os problemas e as experiências satisfatórias) são independentes das deficiências e mais arraigados às políticas do processo inclusivo.

\section{MÉTodo}

\section{PARTICIPANTES}

Participaram deste estudo 4 mães que têm filhos com Paralisia Cerebral, 4 mães que têm filhos com Síndrome de Down e os 8 respectivos professores dessas crianças, da rede regular de ensino de um município da grande São Paulo. Tais deficiências foram selecionadas em função da sua presença constante em classes do ensino regular, mais do que outras que possuem uma baixa incidência na população. Por exemplo, a SD é a causa genética mais comum de deficiência intelectual e a PC está associada a comprometimentos motores e cognitivos. Desse modo, a análise dos relatos dos pontos de vista de pais e professores sobre a inclusão de crianças com essas deficiências podem evidenciar particularidades e diferenças no processo inclusivo. Como critérios de inclusão na pesquisa, as crianças deveriam ser diagnosticadas com tais deficiências, frequentar escolas regulares do Ensino Fundamental I e ter pais e professores que concordassem em participar do estudo. A caracterização dos participantes pode ser visualizada no Quadro 1, que apresenta as características dos alunos com SD e PC. 


\begin{tabular}{|c|c|c|c|c|c|c|}
\hline Síndrome & Criança & Sexo & $\begin{array}{c}\text { Idade } \\
\text { (anos) }\end{array}$ & $\begin{array}{c}\text { Série } \\
\text { (ano) }\end{array}$ & $\begin{array}{c}\text { Tempo na } \\
\text { escola comum }\end{array}$ & $\begin{array}{c}\text { Passagem pela escola } \\
\text { especial }\end{array}$ \\
\hline \multirow{6}{*}{ SD } & 1 & $\mathrm{~F}$ & 11 & $4^{\circ}$ & 3 anos & 8 anos \\
\cline { 2 - 7 } & 2 & $\mathrm{M}$ & 8 & $2^{\circ}$ & 1 ano & Não \\
\cline { 2 - 8 } & 3 & $\mathrm{M}$ & 12 & $3^{\circ}$ & 3 anos & 9 anos \\
\cline { 2 - 8 } & 4 & $\mathrm{~F}$ & 9 & $4^{\circ}$ & 5 anos & Desde bebê até 3 anos \\
\hline \multirow{3}{*}{ PC } & 5 & $\mathrm{M}$ & 12 & $3^{\circ}$ & 2 anos & 2 anos \\
\cline { 2 - 8 } & 6 & $\mathrm{~F}$ & 11 & $2^{\circ}$ & 2 anos & Desde bebê \\
\cline { 2 - 8 } & 7 & $\mathrm{~F}$ & 8 & $1^{\circ}$ & 8 meses & Não \\
\cline { 2 - 7 } & 8 & $\mathrm{~F}$ & 10 & $4^{\circ}$ & 4 anos & \\
\hline
\end{tabular}

Quadro 1- Características dos alunos com SD e PC participantes da pesquisa.

A idade das mães das crianças com SD variou de 25 a 51 anos (média de 37 anos); e das mães das crianças com PC variou de 35 a 42 anos (média de 38 anos). Com relação à escolaridade das mães, três delas possuíam primeiro grau incompleto, uma delas o primeiro grau completo, outra o segundo grau incompleto, duas delas o segundo grau completo e uma o nível universitário. Duas trabalham fora (mãe da criança 2 é auxiliar de enfermagem e da criança 7 é professora) e a maioria tem dedicação exclusiva ao lar.

Dos professores entrevistados somente um tem apenas o magistério (professor da criança 3); os demais, nível universitário na área da educação. Não foi relatada nenhuma formação específica na área das deficiências. Com relação ao tempo de magistério os professores das crianças com PC possuem em média 9,5 anos, os professores das crianças com SD possuem em média 8,0 anos, existindo professores com 22 anos de experiência (como o professor da criança 1) e com 2 anos (como o professor da criança 4).

\section{INSTRUMENTO E PROCEDIMENTOS}

O instrumento utilizado foi uma entrevista estruturada, para a qual foram elaboradas questões abertas e relevantes ao tema pesquisado. As perguntas foram construídas pelos pesquisadores, com base nos objetivos específicos, e adaptadas especificamente para mães e professores (Quadro 2). 


\begin{tabular}{|c|c|c|}
\hline Objetivos específicos & $\begin{array}{l}\text { Perguntas para } \\
\text { professores }\end{array}$ & $\begin{array}{l}\text { Perguntas para } \\
\text { mães }\end{array}$ \\
\hline $\begin{array}{l}\text { Conhecer as expectativas } \\
\text { relatadas pelos professores e mães } \\
\text { em relação ao processo de } \\
\text { inclusão e escolarização de } \\
\text { crianças com PC e SD. }\end{array}$ & $\begin{array}{l}\text { 1-O que espera da escolarização } \\
\text { do aluno? }\end{array}$ & $\begin{array}{l}\text { 1-O que espera da escola, em } \\
\text { relação ao seu filho? }\end{array}$ \\
\hline $\begin{array}{l}\text { Conhecer as informações que os } \\
\text { mães possuem sobre o trabalho } \\
\text { realizado com seus filhos com SD } \\
\text { e PC e como os professores } \\
\text { avaliam seu trabalho. }\end{array}$ & $\begin{array}{l}\text { 2-O aluno participa das } \\
\text { atividades da sala? } \\
\text { 3-Quais são as atividades } \\
\text { desenvolvidas? Como são } \\
\text { escolhidas? } \\
\text { 4-Como você avalia a efetividade } \\
\text { (aprendizado) dessas atividades? }\end{array}$ & $\begin{array}{l}\text { 2-Seu filho participa das } \\
\text { atividades da sala? } \\
\text { 3-Quais são as atividades } \\
\text { desenvolvidas? Você sabe como } \\
\text { são escolhidas? } \\
\text { 4-Como você avalia a efetividade } \\
\text { (aprendizado) dessas atividades? }\end{array}$ \\
\hline $\begin{array}{l}\text { Conhecer como a comunicação } \\
\text { entre pais e professores que têm } \\
\text { alunos com SD ou PC é relatada } \\
\text { por eles. }\end{array}$ & $\begin{array}{l}\text { 5-Como é seu contato com os pais } \\
\text { do aluno? }\end{array}$ & $\begin{array}{l}\text { 5-Como é seu contato com a } \\
\text { professora? }\end{array}$ \\
\hline $\begin{array}{l}\text { Identificar o conhecimento e a } \\
\text { opinião sobre o processo de } \\
\text { inclusão. }\end{array}$ & $\begin{array}{l}\text { 6-Para você, o que é inclusão? } \\
\text { 7-Qual sua opinião sobre o } \\
\text { processo de inclusão de seu } \\
\text { aluno? }\end{array}$ & $\begin{array}{l}\text { 6-Para você, o que é inclusão? } \\
\text { 7-Qual sua opinião sobre o } \\
\text { processo de inclusão de seu filho? }\end{array}$ \\
\hline
\end{tabular}

Quadro 2 - Roteiro de entrevista estruturada para mães e professores, com respectivos objetivos

Os procedimentos metodológicos aqui descritos foram submetidos e aprovados pelo Comitê de Ética em Pesquisa Envolvendo Seres Humanos da Universidade Presbiteriana Mackenzie (Processo CEO/UPM no 1145/05/2009 e CAAE $n^{\circ}$ 043.0.272.000-09). Inicialmente foi solicitada a autorização da Secretaria de Educação do Município, para que posteriormente fosse feito um contato com a direção da escola. Na sequência, foi feito o contato com o professor. As entrevistas duraram aproximadamente uma hora cada, gravadas em áudio ou respondida sob a forma de questionário, sobre os quais posteriormente se conversava para dirimir quaisquer dúvidas das respostas.

Após a leitura do material das entrevistas, foram identificadas as unidades de análise e as categorias que emergiram dos dados de cada um dos grupos de mães e professoras. A leitura das entrevistas de cada grupo possibilitou o agrupamento de categorias por semelhanças temáticas. Os dados das categorias foram descritos em um texto-síntese e interpretados de acordo com os objetivos previstos. A discussão centrouse nas categorias que apresentaram maior frequência (ARAUJO; SPERB, 2009).

\section{Resultados E Discussão}

A primeira pergunta procurou conhecer as expectativas relatadas pelos professores e mães em relação ao processo de inclusão e escolarização de crianças com PC e SD. Verificou-se que as expectativas de aprendizagem esperada pelas 
mães e professores estão relacionadas à alfabetização e socialização. Aparecem também expectativas quanto à independência, havendo referência, em alguns casos, à preocupação com as atividades da vida diária. Tal preocupação pode ser verificada na fala da professora da criança 2, "espero que compreenda as regras de convívio, tenha autonomia para utilizar o banheiro", assim como as mães das crianças 5 e 6 demonstram satisfação com o fato dos filhos estarem na escola e aprenderam a comer sozinhos "esta aprendendo a comer direito e sozinho, ir ao banheiro de pé e a lavar as mãos", "na escola ela progrediu bastante, come sozinha e já sabe limpar a baba".

Quanto à alfabetização, parece haver a preocupação da aprendizagem de pelo menos a escrita do nome, entretanto observa-se que muito pouco já foi conquistado. Esse fato pode ser observado na fala da mãe da criança 1: "tinha a expectativa que em um ou dois anos ela iria aprender a escrever pelo menos o nome, esses [quase] quatro anos que ela esta lá não conhece cores nem letras". A mãe da criança 7 mostra-se insatisfeita com o aprendizado da filha, concluindo: "eu quero que mude a metodologia e recursos para que ela aprenda". Essa mãe privilegia os aspectos metodológicos e pedagógicos como necessários para respaldo do processo ensinoaprendizagem. Rubim (2009), ao entrevistar 60 pais de alunos com SD identificou, com este trabalho, que a expectativa dos pais sobre a inclusão é que a escola possa alfabetizar, preparar para o trabalho, socializar, educar, desenvolver habilidades.

Os dados da pergunta 2 demonstram que os alunos com SD e PC, participam das atividades em sala de aula, porém atividades específicas de escrita contam com a ajuda de colegas e com as tentativas da criança, não significando que saibam, muitas vezes, o que estão fazendo. Este fato fica claro quando algumas professoras relatam que "atividades em folhas têm sempre ajuda dos colegas". A mãe da mesma criança afirma o ocorrido: "negócio de festas, ajudar a professora a colar coisinhas ela faz, agora caderno de lição, nada. A professora da criança 6 descreve que a criança "participa de tudo, mas, nas atividades de escrita não demonstra interesse, ora rabisca, ora coloca embaixo da mesa". Pode ser observado, neste caso, que a criança com deficiência na hora de realizar atividades relacionadas com registros escritos demonstra desinteresse, talvez uma forma de demonstrar que a atividade está além daquilo que ela é capaz de fazer. Outra questão, que é de grande importância ressaltar, está relacionada ao fato de não se criarem estratégias para facilitar a participação do aluno em todas as atividades. Por exemplo, em se tratando de crianças com PC, o uso da cadeira de rodas pode tornar-se um transtorno, como no relato do professor da criança 5: "o aluno tinha uma participação melhor antes do uso da cadeira de rodas". A mãe diz ter ciência de que o filho não participa das atividades de educação física e biblioteca devido à dificuldade do acesso. Sobre esse fato, quando é questionada sobre o que é feito durante essas aulas, ela diz: "ele fica na sala ou no pátio, sozinho e esperando, vizinhos já o viram chorar". Em todos os relatos foi identificado que a participação dos alunos em sala de aula ocorre em atividades que evidenciam a socialização; por outro lado, as atividades pedagógicas direcionadas à alfabetização não encontram participação efetiva dos alunos. 
Ao serem indagadas sobre quais são as atividades desenvolvidas e como são escolhidas (Pergunta 3), pôde ser observado que não há um critério de escolha entre os professores. Alguns dão atividades diferenciadas, e outros, as mesmas atividades para todos os alunos. Alguns professores realizam atividades de acordo com a necessidade do aluno. Para uma criança com PC, justifica-se a utilização de atividades diferentes pela necessidade de desenvolver a coordenação motora fina. Assim, a professora da criança $7 \mathrm{diz:}$ "dou preferência para atividades de recorte, alinhavo, perfuração". Para crianças com SD, as atividades são diferenciadas em função do déficit intelectual, pois não conseguem acompanhar os demais alunos da sala. A professora do aluno $5 \mathrm{diz}$ trabalhar com atividades direcionadas, porém essas atividades não são constantes e, devido ao elevado número de alunos em sala de aula, não consegue dar atenção necessária a ele.

Há também professores que aplicam as mesmas atividades dadas para os alunos com dificuldades de aprendizagem ao aluno com deficiência. Eles consideram essa estratégia adequada, para resolver as dificuldades encontradas em sala de aula. Por exemplo, a professora da criança 1 afirma: "não escolho atividades diferentes, procuro trazer as mesmas atividades que aplico para alunos com defasagem de aprendizagem". Esse também é o caso da professora da criança 8, que criou uma apostila para trabalhar com a aluna incluída em sua sala e com alunos não alfabetizados que estão no $4^{\circ}$ ano. Quanto à importância de trabalhar as mesmas atividades, a professora da criança 8 destaca: "as atividades são iguais para todos, devido ao contexto de inclusão". Para a professora da aluna 6, ela deverá realizar as mesmas atividades que os demais alunos, seguindo-se a orientação dada pela Secretaria Municipal de Educação.

Do ponto de vista das mães, a da criança 4 aponta que o trabalho diferenciado é dificultado pelo número de alunos em sala de aula, dizendo: "o professor dá atividades de acordo com a necessidade da minha filha, escrevendo no caderno e colocando ao lado da mesa dele, é uma forma de dar conta dela e da sala". A mãe da criança 3 considera que: "dar a mesma atividade para todos é uma atitude correta para não discriminar, porém precisaria de alguém para auxiliar, ele (o aluno) deixa as atividades pela metade".

Destaca-se também que as atividades escolhidas dão preferência a atividades escritas, como caça palavras, cruzadinhas e textos, atividades que parecem difíceis para alunos não alfabetizados. Os professores têm a preocupação de cumprir o planejamento escolar, tendo receio de trabalhar diferenciadamente o que foi programado para o ano letivo. Desse modo, a criança com deficiência recebe outras atividades quando a professora consegue ocupar os outros alunos. Assim, ela pode dedicar-se um pouco mais à criança, oferecendo-lhe atenção individualizada. Por outro lado, atividades extras, quando dadas, devem ser feitas em casa, com a colaboração da mãe, alternativa encontrada por algumas professoras para tentar melhorar o aprendizado do aluno em comparação com os colegas de sala.

Leonardo (2008), ao pesquisar a inclusão em escolas públicas, concluiu que os professores não estão aptos para trabalhar com a diversidade, o que os leva 
a se sentirem inseguros, preocupados e desamparados. Segundo o autor, há falta de projetos inclusivos, conhecimento específico, estratégias e metodologias de ensino adequadas, comprometendo a aprendizagem e o desenvolvimento do aluno com deficiência em sala de aula.

Quanto à avaliação da efetividade do aprendizado (Pergunta 4), foi observado que a maioria das mães considera essa efetividade ruim, uma vez que alfabetização não está sendo conquistada por seus filhos. Tal fato pode ser identificado na fala de algumas mães, como na da criança 3: "ele não consegue ler e se perde totalmente". A mãe da criança 1 considera ruim porque a professora não tem condições de ensinar uma sala com 46 alunos, apontando como necessidade a ajuda de um professor auxiliar, e a mãe da criança 7 também refere que "o objetivo final, que é o da aprendizagem, ela não está alcançando".

Fica claro que as mães consideram o aprendizado ruim, uma vez que a alfabetização foi apontada como expectativa de aprendizagem. Para a professora da criança 4 , seria preciso considerar o que a aluna é capaz de fazer, pois está em um $4^{\circ}$ ano e consegue fazer atividades de $1^{\circ}$ ano. Para alguns professores, parece haver progressos quanto à aprendizagem do aluno. A professora da criança 5 considera: "se pensarmos na evolução ao montar um quebra-cabeças, podemos afirmar que sua aprendizagem é lenta, porém satisfatória". Observa-se uma fala semelhante quando a professora da aluna 1 diz que o simples fato de a aluna conhecer uma letra é um avanço: "a cada letra reconhecida considero um avanço importante". Pode-se concluir que a socialização não é mais a única preocupação de mães e professores; é esperado que as crianças aprendam o que a escola tem para ensinar.

Quanto ao modo de contato entre pais e professores (Pergunta 5), tanto para as crianças com PC, como para as com SD, na sua maioria, verificou-se que é feito por meio de caderno de recados, nos quais os professores registram comunicados gerais da escola ou solicitam a presença da mãe e os pais quando querem mandar algum recado para o professor. Entretanto, a mãe da criança 7 diz: "eu vou à escola, mas a professora tem sempre uma ocupação e não pode falar comigo". A professora da criança 5 relata: "o contato é quase nulo, ela parece não gostar de ser chamada à escola. No entanto, a maioria acha que reuniões de pais e caderno de recados são recursos suficientes para manter a comunicação entre pais e professores.

Observa-se, entretanto, que o fato de as mães saberem o que é feito em sala de aula e estarem mais presentes na escola parece contribuir com a aprendizagem da criança com deficiência, já que algumas professoras utilizam como estratégia mandar atividades para serem feitas em casa. Assim, para que isso possa ocorrer de maneira adequada, os professores precisam contar com a colaboração da mãe, estabelecendo com ela uma parceria eficiente. A professora da criança 1 diz: "a mãe é exigente e cobra atitudes da escola". Ao mesmo tempo, a mãe diz: "eu tinha que ajudar porque ela não tem condições de cuidar da M. e de mais 45 alunos. A mãe ajuda e cobra atitudes para melhorar a condição da filha dentro da escola, para que a professora possa lhe oferecer atenção necessária. Por outro lado, 
a professora da criança 6 considera que o contato é bom, e a mãe fornece dicas para a professora auxiliar a aluna, como informações sobre seu comportamento, sobre o que gosta ou desperta seu interesse. A professora considera esse fato importante, pois procura, direcionar as atividades com o que pode vir chamar a atenção da aluna e, assim, conseguir sua participação junto ao grupo.

A mãe da criança 4 também acredita ser importante oferecer informações ao professor: "dou umas dicas para ele saber lidar com ela, converso com todos da escola. As informações são muito importantes, porque ajuda o professor a conhecer mais rápido o que a gente já sabe." A professora da criança 4 considera importante esse contato para manter uma parceria no trabalho desenvolvido com a criança " $A$ mãe da $A$. desde o começo sempre foi muito presente e preocupada, a nossa relação era positiva, pois nos ajudávamos mutuamente.

Luiz e colaboradores (2008) apontaram que a boa interação dos pais com a escola é primordial fator positivo, pois eles têm experiências e habilidades para ensinar o próprio filho. No mesmo sentido, Silva e Mendes (2008) descrever a importância da interação dos profissionais da escola e dos familiares de crianças com deficiência para propiciar e manter uma parceria colaborativa, efetiva e bem sucedida.

Para Rubim (2009), a família deve ser vista como uma aliada da escola, pois ela também se apresenta como um sistema construído historicamente, cujas atitudes e formas de pensamento refletem aspectos políticos, filosóficos, sociais e culturais que devem ser considerados nas propostas político-pedagógicas da escola. Dessa forma, quando a mãe da criança 5 diz: "Se tivesse um horário determinado para gente conversar seria melhor, porque em reunião é muita gente e na entrada e saída é correria", revela-se uma alternativa importante para diminuir algumas dificuldades em sala de aula, pois essas "dicas" foram referidas como valiosas nesse processo. O professor pode gastar muito tempo para conhecer o aluno, chamar sua atenção e envolvê-lo nas atividades, enquanto as informações dadas pelas mães possibilitam a formulação de estratégias, fazendo com que o professor busque atividades com base naquilo que atrai sua atenção. A escola deve incentivar a parceria dos pais com os professores, criando momentos para troca de informações, pois de acordo com os resultados deste trabalho informações e contribuições dadas pelas mães ajudam a criança com deficiência a permanecer na escola, tornando-se uma estratégia de eficácia para a inclusão.

Os dados apresentados na pergunta 6 registram que todas as mães vêem a inclusão como a maior oportunidade para diminuir preconceitos. Em todos os depoimentos foram expressos a angústia e o medo de enfrentar o preconceito. A mãe da criança 4 relata que, um dia, indo para escola escutou "lá vem a doidinha", e aponta tal fato como sendo reflexo do desconhecimento dos pais sobre seu filho. Por esse motivo, dispõe-se a aproveitar reuniões de pais para falar sobre a síndrome da filha, acreditando que o esclarecimento é o melhor caminho para a quebra de preconceitos. A mãe da criança 3 fala do preconceito e do desconhecimento: "ainda há mães que não entendem, é ignorância, não sabe o que é a SD". 
Em pesquisa realizada por Martins (1999) verificou-se que convivência com colegas com SD proporcionou maior grau de interação na turma, construção de vínculos afetivos e a diminuição de preconceitos e estereótipos em relação aos colegas com a síndrome. $\mathrm{O}$ conhecimento das consequências da interação dos alunos com necessidades especiais e seus colegas de turma pode influenciar a diminuição de julgamentos com base em concepções discriminatórias e preconceituosas e, dessa forma, contribuir para o estabelecimento de políticas de inclusão social. De acordo com esse pensamento, há o depoimento da mãe da criança 7: "incluir é tudo, em todos os aspectos, social, e de aprendizagem". Algumas mães não declaram abertamente o preconceito das outras pessoas em relação aos seus filhos, mas ele se torna perceptível quando declaram: "é uma forma de mostrar a população que são pessoas iguais, com direito de irem a parques e restaurantes" (mãe da criança 5). A mãe da criança 8 acha a inclusão algo natural, porém em seu depoimento aparece o medo da filha estar no meio de todos: "eu tive um bloqueio em trazer ela para escola porque eu achava que ela iria ficar de lado, se todos souberem o que é uma criança especial perde-se o medo".

Aparecem apontamentos que exigem estrutura adequada para o sucesso da inclusão: "inclusão é mais professores para ajudar, formação para aqueles que não conhecem o deficiente, é uma coisa boa, mas se fosse bem feita" (mãe da criança 1). Para os professores, a inclusão é um direito, e eles concordam que há necessidade de recursos. Vêm o indivíduo como um membro da sociedade, respeitam seus limites e percebem que ele busca autonomia.

Os relatos obtidos, nas entrevistas de mães e professores, sobre o processo específico de inclusão da criança (Pergunta 7), demonstram que a socialização e aceitação das outras pessoas garantem a satisfação das mães, porém elas não descartam a necessidade de apoio e recursos para melhorar a condição do aluno na escola, acreditando ser o caminho para a aprendizagem, ou seja, ler e escrever. A mãe da criança 8 considera que frequentar a escola regular tem sido bom, "se ela erra uma outra criança a corrige, talvez não teria as mesmas oportunidades em uma escola especial", da mesma forma aponta a mãe da criança 4 "ela lida bem com as pessoas, sempre espero mais da escola, os professores precisam aprender a lidar com a minha filha e se adequar a esse novo tempo." A mãe da criança 7 tem grande expectativa quanto à aprendizagem, mas não observa que esse fato vem ocorrendo: "para mim, a inclusão não acontece, eu não consigo ver algo de aprendizagem, aceitaram por aceitar e tentam trabalhar". A professora da mesma aluna aponta que a falta de recursos e de orientação dificulta sua atuação, pois não sabe como trabalhar com a aluna.

Os professores entrevistados apontam como necessária a formação para trabalharem com essas crianças e a disponibilidade de recursos, como garantia de qualidade de ensino: "acredito que dentro da escola deveríamos ter mais recursos, haver formação para os professores, dessa forma poderíamos dar uma educação de melhor qualidade para nossos alunos" (professora da criança 3). A professora da criança 2 acha necessário um professor auxiliar, para que possa realizar as atividades com todos os alunos. A professora da criança 5 vai além da simples aceitação, pois acredita que a identificação com esses alunos é importante. 
Pode-se perceber que, diferentemente da opinião dos professores das crianças com SD, os professores das crianças com PC parecem encontrar muita dificuldade, em decorrência das próprias características da deficiência. A fragmentação da comunicação das professoras com as mães dificulta a comunicação da professora com o aluno em sala. Parece existir uma barreira e ainda certo preconceito com esse grupo de crianças, o que impossibilita estabelecer uma comunicação eficaz a favor do desenvolvimento da criança. Os professores dizem que a falta de apoio, formação e recursos é que determinam que a inclusão desses alunos seja considerada ruim.

Deve-se considerar que o papel dos pais e seu bom relacionamento com a escola são de fundamental importância no processo inclusivo. Luiz e colaboradores (2008) analisaram artigos provenientes da Nova Zelândia, Holanda, Reino Unido e Estados Unidos sobre a inclusão de crianças com SD na rede regular de ensino e apontaram a boa interação dos pais com a escola como primordial fator positivo, pois eles têm experiências e habilidades para ensinar o próprio filho. Outro fator que deve ser considerado é o apoio oferecido aos pais no decorrer do processo de inclusão da criança na escola, assim como o apoio adicional oferecido à própria criança. Ainda de acordo com tal trabalho, o professor é apontado como figura fundamental para favorecer o processo da inclusão da criança com SD na escola regular. É ele quem vai detectar no dia a dia quais ajustes podem e devem ser feitos no ambiente, é quem vai criar situações de interação da criança com outros colegas, bem como situações satisfatórias para a criança desenvolver uma boa convivência social.

De acordo com os pressupostos teóricos já apontados, Freitas (2006) observa que a inclusão significa modificação da sociedade como pré-requisito para a pessoa com necessidades especiais buscar seu desenvolvimento e exercer sua cidadania. Desse modo, há que se preparar a escola para incluir nela o aluno com deficiência, a fim de que os benefícios sejam múltiplos para todos os envolvidos com a educação: os alunos, suas famílias, os professores e a sociedade.

\section{Conclusões}

Os resultados apresentam informações importantes referentes à inclusão dos alunos com SD e PC no ensino fundamental. Primeiramente, o que mais foi abordado pelas mães e professores foi a oportunidade de se diminuir o preconceito, pois, mesmo com todos os movimentos existentes a favor da inclusão, muitos ainda vivenciam situações de discriminação. Os resultados encontrados revelam também a expectativa das mães em matricular o filho na escola comum, com a possibilidade de ele aprender a ler e a escrever. Esperam que o filho conquiste no mínimo a escrita do nome. Por outro lado, os professores declaram não se sentirem preparados para trabalhar com alunos com deficiências; no entanto, mesmo sem orientações, recursos e estrutura física adequada, trabalham para melhorar as condições dos alunos em sala de aula. 
É também possível considerar que a escola muitas vezes não cria oportunidades para que pais e professores consigam compartilhar informações e estratégias para ajudar nesse processo. Os encontros estão sempre relacionados a problemas ocorridos. A comunicação ocorre durante as reuniões de pais e mestres ou por meio do caderno de recados. Mesmo para aqueles que exibem melhor comunicação, fica evidente que é uma forma encontrada pelo professor para pedir ajuda aos pais, no que se refere às atividades extras, na tentativa de aproximar a aprendizagem do aluno com SD ou PC à dos demais alunos da sala. Seria oportuno criar momentos para que o professor pudesse estabelecer uma comunicação com os pais, visto que os dados obtidos neste trabalho mostraram que as informações e o apoio dado pelas mães são necessários, pois contribuem no desenvolvimento da criança com deficiência, em sala de aula.

No que se referem às atividades, elas estão voltadas para o que é melhor para todos os alunos, não havendo adaptações e planejamento para o aluno com deficiência. Quando diferenciadas, as atividades estão voltadas para o aluno com deficiência e para um grupo que apresenta dificuldades de aprendizagem, o que mostra que as dificuldades em sala de aula não são direcionadas ao ensino de um aluno com deficiência. Quando se fala em criar estratégias na escola é porque aparentemente a inclusão parece um "problema" do professor que tem o aluno com deficiência em sala, e não responsabilidade de todos. A inclusão foi vista desempenhando somente o papel social; a escola não está conseguindo desenvolverse além dessa função, para transformar-se em transmissora da cultura e em promotora da autonomia e da criticidade em seus alunos.

A inclusão ainda é um processo em todos os lugares, e o processo se vive, se aprende, com correção das falhas. Enquanto a inclusão estiver dentro dos moldes burocráticos e regidos por ordens superiores, como as determinações políticas que muitas vezes desconhecem a realidade, os avanços não se concretizarão. Assim, para que isso aconteça é preciso resolver os problemas atuais e construir, eliminando as falhas, as quais estão escondidas na realidade inclusiva, uma vez que a escola se constitui por uma ampla dimensão de características individuais que não são consideradas.

A inclusão não deve ser efetivada sem que se considerem as condições em que será desenvolvida. Deverá ser verificado o que pode ser oferecido para diminuir as dificuldades trazidas pela deficiência. Atender às necessidades educacionais do aluno com PC e SD é antes de tudo saber de que maneira a escola poderá responder a essas necessidades para intervir pedagogicamente de forma adequada. Partindo do princípio da inclusão, de que todos devem aprender juntos, todas as escolas estão sujeitas a receber alunos com deficiência; portanto, prepararse previamente para isso é essencial para minimizar as dificuldades encontradas. Assim, a escola deve levar a aprendizagem de fato, e não a promover um sistema que gera uma nova exclusão.

É possível concluir, então, que a escola deve possibilitar condições para que os pais e professores se comuniquem de forma adequada, ou seja, troquem informações 
constantemente, participem de reuniões específicas para falar sobre o aluno com deficiência ou organizem horários para que isso aconteça. É importante destacar que essas iniciativas não garantem a construção de educação inclusiva, visto que os professores precisam de suporte de várias ordens para trabalhar adequadamente em sala de aula, porém é um caminho que contribui para minimizar tantas dificuldades.

\section{REFERÊNCIAS}

ARAUJO, G. B.; SPERB, T. M. Crianças e a construção de limites: narrativas de mães e professoras. Psicologia em estudo, Maringá, v.14, n.1, p. 185-194, 2009.

ARSENIO, I. Análise dos obstáculos à inclusão escolar da pessoa com deficiência: uma revisão da literatura especializada. São Carlos: Suprema, 2007.

ARTIOLI, A, L. A educação do aluno com deficiência na classe comum: a visão do professor. Psicologia da Educação, n. 23, p. 103-121, 2006.

BOBATH, K. A deficiência motora em pacientes com paralisia cerebral. São Paulo: Manole, 1979.

BRASIL. Ministério da Educação. Saberes e práticas da inclusão: desenvolvendo competências para o atendimento às necessidades educacionais de aluno com deficiência física/neuromotora. 2.ed. Brasília: MEC, Secretaria de Educação Especial, 2006.

BRASIL. Política nacional de educação especial na perspectiva da educação inclusiva. MEC/SEESP, 2007.

CUNNINGHAM, C. Síndrome de Down: uma introdução para pais e cuidadores. Trad. Ronaldo Cataldo Costa. 3. ed. Porto Alegre: Artmed, 2008.

FONSECA, L. F; LIMA, C. L. A. Paralisia cerebral. 2. ed. Rio de Janeiro: MedBook, 2008.

FREITAS, S. N. A formação de professores na educação inclusiva: construindo a base de todo o processo. In: RODRIGUES, D. (Org.). Inclusão e educação: doze olhares sobre a educação inclusiva. São Paulo: Summus, 2006.

GERALIS, E. Crianças com paralisia cerebral: guia para pais e educadores. Trad. Maria Regina Lucena Borges-Osório. 2. ed. Porto Alegre: Artmed, 2007.

GOMES, C.; BARBOSA. A. J. G. Inclusão escolar do portador de paralisia cerebral: Atitudes de professores do ensino fundamental. Revista Brasileira de Educação Especial, Marília, v.12, n.1, p.85-100, 2006.

LEONARDO, N. S. T. Inclusão escolar: um estudo acerca da implantação da proposta em escolas públicas. Psicologia Escolar e Educacional, Campinas, v.12, n.2, 2008.

LUIZ, F. M. R. et al. Inclusão da criança com Síndrome de Down na rede regular de ensino: desafios e possibilidades. Revista Brasileira de Educação Especial, Marília, v.14, n.3, p.497508, 2008.

MARINS, S. C. F.; MATSUKURA, T. S. Avaliação de políticas públicas: a inclusão de alunos com necessidades educacionais especiais no ensino fundamental das cidades-pólo do Estado de São Paulo. Revista Brasileira de Educação Especial, Marília, v.15, n.1, p.45-64, 2009.

MARTINS, L. A. R; MELLO, F. R. L. V. Acolhendo e atuando com alunos que apresentam paralisia cerebral na classe regular: a organização da escola. Revista Brasileira de Educação Especial, Marília, v.13, n.1, p.111-130, 2007.

MARTINS, L. A. R. Integração escolar do portador da Síndrome de Down: um estudo sobre a percepção dos educadores. Revista Brasileira de Educação Especial, Piracicaba, v.5, p. 73-85, 1999.

MELO; E. P.; ROCHAI, M. L. Poder e trabalho na escola: práticas inclusivas em discussão. 
Psicologia em Revista, v. 14, n. 2, p. 81-94, 2008.

MILLS, N. D. A educação da criança com Síndrome de Down. In: SCHWARTZMAN, J. S. 2. ed. Síndrome de Down. São Paulo: Memnon: Mackenzie, 2003.

OMOTE, S. Aparência e competência em Educação Especial. Temas em Educação Especial. São Carlos: UFSCar, v.1, p.11-26, 1990.

PUESCHEL, S. M. Síndrome de Down: Guia para pais e educadores. 12. ed. Trad. Lúcia Helena Reily. Campinas: Papirus, 2007.

RIBEIRO, D. F., ANDRADE; A. S. A assimetria na relação entre família e escola pública. Revista Paidéia, v.16, n. 35, p. 385-394, 2006.

RUBIM, D. L. M. Pais de alunos com Síndrome de Down: significados atribuídos à inclusão escolar e expectativa de escolarização. 2009. Dissertação (Mestrado) - Universidade Presbiteriana Mackenzie, São Paulo.

SATOW, S. H. Paralisado cerebral: construção da identidade na exclusão. 2.ed. São Paulo: Cabral Editora Universitária, 2000.

SCHWARTZMAN, J. S. Síndrome de Down. 2. ed. São Paulo: Memnon: Mackenzie, 2003.

SHERMAN, S.L. et al. Epidemiology of Down Syndrome. Mental Retardation and Developmental Disabilities Research Reviews, v.13, p.221-227, 2007.

SILVA, A. M.; MENDES; E. G. Família de crianças com deficiência e profissionais: componentes da parceria colaborativa na escola. Revista Brasileira de Educação Especial, Marília, v.14, n. 2, p. 217-234, 2008.

SOUZA, C. C. Concepção do professor sobre o aluno com paralisia cerebral e sua inclusão no ensino regular. 2005. Dissertação (Mestrado em Educação) - Universidade do Estado do Rio de Janeiro, Rio de Janeiro.

SOUZA, J. M. M. Crianças com necessidades educativas especiais como membro da sociedade e sua inclusão no contexto escolar: estudo de caso comparativo entre Brasil e Portugal. 2007. Dissertação (Mestrado) - Universidade do Minho, Portugal.

STRAY-GUNDERSEN, K. Crianças com sindrome de down: guia para pais e educadores. Trad. Maria Regina Lucena Borges-Osório. Porto Alegre: Artmed, 2007.

TEIXEIRA. F. C.; KUBO. O. M. Características das interações entre alunos com Síndrome de Down e seus colegas de turma no sistema regular de ensino. Revista Brasileira de Educação Especial, Marília, v.14, n.1, p.91, 2008.

UNESCO. Declaração de Salamanca e linha de ação sobre necessidades educativas especiais. Brasília: CORDE, 1994.

VITALIANO, C. R. Análise da necessidade de preparação pedagógica de professores de cursos de licenciatura para inclusão de alunos com necessidades educacionais especiais. Revista Brasileira de Educação Especial, Marília, v.13, n.3, p.399-414, 2007.

VOIVODIC, M. A. M. A. Inclusão escolar de crianças com Sindrome de Down. 5. ed. Petrópolis: Vozes, 2008.

Recebido em: $16 / 03 / 2010$

Reformulado em: 13/10/2010

Aprovado em: 04/11/2010 